\title{
Influence of Socio-Demographic Characteristics of Juvenile Recidivists on Their Reoffending
}

\author{
Sebastian Okello Wang'ombe \\ Kibabii university, P.o Box 1699 - 50200 , KENYA
}

\begin{abstract}
The Government of Kenya introduced rehabilitation institutions to deal with rehabilitation of child offenders and prevent them from recidivating. While statistics indicate juvenile crime and recidivism to be on the increase, studies on the phenomenon of recidivism among juveniles in correctional institutions in Kenya are scanty. The purpose of this study was to establish the influence of socio-demographic characteristics on recidivism among juveniles in rehabilitation institutions in Kiambu and Kirinyaga counties of Kenya. The objectives of the study were to establish the influence of Juvenile recidivist's socio-demographic characteristics on their recidivism. The study was based on Robert Merton's 1938 strain theory. The study adopted a descriptive survey research design. The target population for the study was 333 juvenile recidivists and 60 correctional staff in Wamumu and Kirigiti rehabilitation schools in Kirinyaga and Kiambu counties of Kenya respectively. The data for the study was collected by use of questionnaires, Focused Group Discussion, in-depth interview schedules and document analysis and analyzed using descriptive statistics. The study found negative peer influence and level of education reached to be the child offender's social and demographic characteristics respectively that had the highest influence on recidivism among child offenders in Kiambu and Kirinyaga counties of Kenya. The study recommended change in design of juvenile rehabilitation programmes to take into consideration juvenile's socio-demographic characteristics and; needs and risks facing him. This is combination of both institutional and community based intervention and supervision that tap into youth potential and steer them away from crime.
\end{abstract}

Keywords: Socio-Demographic, Characteristics, Juvenile, Reoffending

DOI: $10.7176 /$ PPAR/9-6-01

Publication date:June $30^{\text {th }} 2019$

\section{Introduction}

Owing to the increasingly growing problem of juvenile crime and recidivism; and the recognition that adult criminals begin their criminal careers in their juvenile years, the need to contain juvenile offending has never before been so glaring. Delinquency of young offenders can be predicted, prevented and treated. But the methods most often used to predict, prevent and treat juvenile delinquency typically derive from stereotypical conceptions, which often yield very low accuracy levels because of lack of empirical researches on the subject (Mbuba, 2004). A study on 20-year trends in juvenile detentions, correctional and shelter facilities in the United States showed that "there were more juveniles... in more crowded, secure, and costly juvenile correctional facilities in 1995 than there were in the preceding years" (Smith, 1998:539). Furthermore, violent crimes are being committed by younger and younger persons and are even increasing among middle-class youth in suburban neighborhoods and communities in United States (Durant, 1999:268).

In 2000 the number of arrests for persons under 18 years in the United States stood at a staggering 1,560,289. Out of these, those charged with violent crimes such as murder, non-negligent manslaughter, forcible rape, robbery, and aggravated assault were 65,910 while those charged with property crimes, including, burglary, larceny-theft, motor vehicle theft, and arson, were 345,731 ( Pastore \& Maguire, 2002:352).

Recent studies on juvenile court statistics and prediction of recidivism tend to show a preponderance of delinquency among youths aged 15 or younger for all the cases processed by the juvenile courts (Katsiyannis and Archwamety, 1997; Archwamety and Katsiyannis, 1999; Puzzanchera, et al., 2003; Katsiyannis et. al, 2004). Although the number of cases involving 17-year-olds may be depicted as lower than the number involving 16year-olds, this may owe to the fact that in some states 17-year-olds are legally treated as adults and are therefore processed in adult courts rather than in juvenile jurisdictions, But even after controlling for the age of majority factor, the younger age brackets at the time of first adjudication are more represented in both offending and reoffending (Duncan et al., 1995). This claim is further corroborated by Miner (2002), who, in a study of predictors of recidivism in serious juvenile sex offenders, found that youths who began offending at younger ages were at increased risk of reoffending. Conversely, an inverse relationship exists between the age at release and the likelihood of recidivism.

The type of the offense for which a person was released from custody or state supervision has been shown by previous research to be an important factor in whether or not the person will engage in further criminal or delinquent behavior upon release (Corrado, et al., 2003). Juveniles who commit violent offenses are more likely than minor and property offenders to commit additional offenses, both violent and non-violent (Duncan et al., 1995; Sabol, et al., 2000; Bondeson, 2002). In an eight-year comparative analysis of adolescent rapists and child 
molesters, Hagan et el. (2001), found adolescent sex offenders to have a significantly higher likelihood of reoffending after release from Correctional facility than a control group of other non-sex offending adolescent delinquents. But in a sharp contrast a recent study has diametrically disputed this offense type- recidivism nexus and argued in the reverse order.

Family stability, often defined from the point of view of whether or not both parents are living together with their siblings, is the single most important factor in ensuring that a child is properly assimilated into the mainstream of society. The influence of the family in reducing or encouraging recidivism stems from the notion of social control, where it is believed that parental influence is capable of counteracting negative swings in adolescents and forms a potential barrier to delinquent behavior (Warr, 1993). Warr also argues that an attachment to parents helps inhibit the initial formation of delinquent friendships, which itself helps interrupt the cycle of negative peer influence and delinquent behaviour

A large body of research has successively and steadily linked peer influence to patterned delinquent behavior, with peer pressure forming a central explanation of not only the first involvement in delinquency, but also the repetitive pattern that typifies recidivism (Loeber \& Loeber, 1987; Warr \& Stanford, 1991; Warr, 1993; Thornberry, et al., 1995; Matsueda \& Anderson, 1998; Benda, 2001; National Research Council \& Institute on Medicine, 2001). Indeed, delinquent peers and delinquent behavior have been found to be reciprocally related; delinquent peer association's foster future delinquency and delinquency increases the likelihood of associating with delinquent peers (Matsueda \& Anderson, 1998:269).

Kinyua (2010) found out that Central Kenya region especially Kiambu and Kirinyaga counties had recorded significant increase in cases of children offending and reoffending between the years of 2008-2012. The free flow of money generated from criminal and juvenile gangs encourages many young men and women to abandon school and engage in criminal activities. Kirinyaga, Muranga and Kiambu districts of Kenya had the highest number of young people engaging in drug and alcohol abuse in the Kenya.

\section{Statement of the Problem}

Juvenile crime and recidivism is a new social problem facing many countries of the world including Kenya. In the United States of America, between 2000 and 2002, about 2, 345, 653 juvenile recidivists had been arrested for more than once for engaging in criminal activities. In Norway during the same period more than 45 percent of juveniles in juvenile correctional institutions were recidivists. In South Africa, the problem was even more critical with more than 47 percent of juveniles reoffending a year after release from rehabilitation institutions (Pastore \&Maguire 2000:343). Lavera (2002) found out that over 35 percent of child offenders in Kenya's rehabilitation schools had reoffended just within one year after reintegration during 1999/2000 fiscal year. According to DCS (2012), out of the total number of child offenders who underwent treatment in rehabilitation schools in 2003, 22\% of boys and $14 \%$ of girls re-offended. The high rate of juvenile recidivism in the Kenya have resulted into family conflicts, property damage and loss, lost investment opportunities, physical injury and loss of life and; psychological and emotional wounds resulting into underdevelopment of the country and long period of suffering on the part of offender and victim. Children have continued to commit heinous criminal acts such as murder, rape, arson, defilement and trafficking in drugs. Reduced juvenile recidivism would contribute to a safe country which will result into more investments resulting into more employment opportunities, stable families and therefore economically and socially stable citizens. Peterson (2009) observed that causes of juvenile recidivism vary from one region to another and are diverse. While statistics indicate juvenile crime and recidivism to be on the increase, studies on the phenomenon of recidivism among juveniles in correctional institutions in Kenya are scanty. It was in view of this that the researcher set out to investigate the socio-demographic characteristics of juvenile recidivists in Kiambu and Kirinyaga Counties of Kenya to determine whether certain socio-demographic characteristics predisposes juvenile offenders to recidivism.

\section{Research Objectives}

The objective of the study was to:-

Determine the influence of juvenile recidivist's socio-demographic characteristics on their reoffending.

\section{Research Questions}

The study sought to answer the following research question:

Which juvenile recidivists' socio-demographic characteristics had influence on their repeat offending?

\section{Review Of Related Literature}

Since juvenile justice policy-makers routinely make use of recidivism as an overriding means of evaluating rehabilitation programs (Gottfredson, 1987), it is important to establish how the individual juvenile recidivists' socio-demographic characteristics impact on recidivism so that they can serve as a yardstick for measuring whether and how well intervention modalities perform in concrete situations. Literature pertaining to the importance of 
such characteristics in the determining rates of recidivism is reviewed below.

Family stability, often defined from the point of view of whether or not both parents are living together with their siblings, is the single most important factor in ensuring that a child is properly assimilated into the mainstream of society. The influence of the family in reducing or encouraging recidivism stems from the notion of social control, where it is believed that parental influence is capable of counteracting negative swings in adolescents and forms a potential barrier to delinquent behavior (Warr, 1993). Warr also argues that an attachment to parents helps inhibit the initial formation of delinquent friendships, which itself helps interrupt the cycle of negative peer influence and delinquent behavior.

Where the offender has assumed delinquent or criminal behavior as a lifestyle of choice, which in other words translates to existence of prior offenses, recidivism rates tend to be higher (Corrado et al., 2003; Nagin \& Paternoster, 1991; Minor, et al., 1999). According to Corrado et al., (2003:184) the import of prior offense or criminal history in predicting recidivism is that the decision to commit further offenses post-release from custody or state supervision "preexists". Prior criminal involvement weakens conventional social bonds thereby damaging those relationships that once helped deter criminal behavior (Wright, et al., 1999). According to Akers (1985), criminal acts and the resultant formal sanctions can give the affected individuals the greater exposure to and affinity for other individuals who constantly violate the law and this patterning of reinforcement leads to elevated participation in further criminal behavior. It has been argued that whether or not prior offense will determine reoffending largely depends on the number and severity of previous offenses, often in the region of five or more times (Snyder, 1998).

Literature reviewed by Cottle et al (2001) shows that marriage and parenthood are a strong basis of social bonds that promote conformity to social and socio-legal norms. Families aid greatly in the construction of social capital, which may be a necessary, though, not necessarily a sufficient ground for remaining law-abiding. Even after a period of interventive treatment, common problem-solving techniques and interaction between family members have been shown to be a major factor in determining whether there will be subsequent offending behavior.

In Andrews and Associates' (1990) meta-analysis, functional family therapy was found to be the leading factor in the reduction of recidivism and this was further corroborated by follow up works on family therapy on delinquency and criminal behavior by Gordon et al. (1995). In a study, Fendrich (1991) concluded that supportive family relationships are likely to reduce repeat delinquent behavior for youth who are on parole or other followup interventions. The relationship between drug use and delinquent behavior has attracted a lot of concern in the last few decades. Although in the public mind the relationship between drugs and crime is often seen as fairly straightforward, with drug use being viewed as directly causing criminal behavior, critical analysis has found the relationship far more complex (McBride \& McCoy, 1997).

A study of alcohol, drugs, and violence showed no significant evidence to suggest that drug use is associated with violence but demonstrated substantial evidence to suggest that alcohol use is significantly associated with violence of all kinds (Parker \& Auerhahn, 1998). However, other studies have found an important association between use of drugs or substance abuse and the rate of offending (Grenier and Roundtree, 1987). Nevertheless, although other studies have attempted to establish the relationship between drug use and offending, they have only showed that offenders are, in general, heavy substance users while heavy substance users are disproportionately likely to engage in criminal activity. In spite of these findings, other recent studies have found positive associations between use of drugs/substance abuse including alcohol and offending, and have thus belied this view, with a conclusion that use of drugs/substance abuse increases the likelihood of offending for young offenders (Loza, et al., 2004).

A large body of research in USA has successively and steadily linked peer influence to patterned delinquent behavior, with peer pressure forming a central explanation of not only the first involvement in delinquency (Loeber \& Loeber, 1987). Indeed, delinquent peers and delinquent behavior have been found to be reciprocally related; delinquent peer association's foster future delinquency and delinquency increases the likelihood of associating with delinquent peers (Matsueda \&Anderson, 1998:269). In a study on the influence of delinquent peers, Warr and Stafford (1991) found that the attitudes of adolescents are influenced by the attitudes and behavior of their peers and those attitudes in turn affect delinquency. In the analysis of the juvenile recidivists' friends, Wakanyua (2005) found out that most children who had offended for the first time were found to have prior association with friends. He revealed that each juvenile recidivist had 4-6 friends. He also found out these peers provided much needed psychosocial and material support.

Njuguna (2007) revealed that there is high prevalence of morbidity among children in rehabilitation schools which he attributed to low socio-economic status, poor family support systems, low education levels and substance use among first juvenile recidivists in rehabilitation schools in Kenya. In addition good proportion of children were in urgent need of psycho social support and psychiatric management as stipulated in section 18,CAP 141 of the laws of Kenya.

The fact that the phenomenon of juvenile offending is worrisome cannot be overstated. However, the delinquency of young offenders can be predicted and could thus be prevented. But the methods most often used 
by correctional officers to predict, prevent and treat delinquency typically derive from conventional wisdom, which often may not stand any scientific verification. The result is that they yield very low accuracy levels, only a little above chance. A more substantive and quantitative-oriented procedure is necessary in order to elevate the effectiveness of prediction and subsequent prevention of juvenile recidivism (Corrado, 2003). This research is based on the assumption that the best way to determine whether a particular socio-demographic characteristic is related to recidivism is to compare the recidivism rates of offenders with that characteristic and that sociodemographic characteristic of offenders varies from one region to another and from across different age sets (Mbuba, 2004). From this review many inconsistencies on which child offender's socio demographic characteristic has the highest influence on their recidivism have been uncovered need for more empirical researches on the phenomenon. The current study sought to fill this gap by carrying out an empirical research which provided more literature about socio demographic characteristics of juvenile recidivism in Kiambu and Kirinyaga counties and revealing which socio demographic characteristic had the highest influence on their recidivism. This finding was to increase the level of accuracy in predicting socio demographic characteristics of juvenile recidivism and providing more literature for future studies.

\section{Research Methodology}

The study employed a descriptive survey research design. In employing a descriptive research design, the researcher sought to examine the influence of socio-demographic characteristics on juvenile recidivism, The decision to adopt a descriptive research design was guided by the observation by Mugenda (2008) that descriptive research designs are commonly used when examining social phenomena that exist in communities. Mugenda noted descriptive studies because of their exploratory nature to be easier and simpler to conduct, yet quite important for providing foundation upon which correlational and experimental studies emerge. Study area for this research was Kiambu County (Kirigiti Rehabilitation School) and Kirinyaga County (Wamumu Rehabilitation School). The target population refers to an entire group of individuals, events or objects having common observable characteristics from which a sample which is a smaller group is obtained (Ahuja, 2001: Mugenda \& Mugenda, 1999). The target population comprised of 333 repeat offenders and 60 correctional officers in two rehabilitation schools. Juvenile recidivists are ex-child offenders who have tendency to revert to criminal behavior soon after their release from juvenile correctional facility. Random sampling table was used to identify the one hundred juvenile recidivists from different strata of 333 repeat juvenile recidivists as respondents. Furthermore, simple random sampling table was used to select 20 correctional officers from a sample size of 60 correctional officers in the selected rehabilitation schools. Respondents were proportionately sampled across the correctional facilities.

The data obtained from the field was organized on the basis of source and serial numbers of the data pieces. The data was then inspected for completeness and then edited or errors. Before coding the data, all the data pieces from all instruments were identified and a list of all of them made.. After entering the data onto a display sheet, descriptive including means, percentages and standard deviations were computed. Qualitative data was received in verbatim, transcribed, organized, reported and recorded in themes and sub themes. All objectives were analyzed by use of descriptive statistics such as percentages. Mean, mode and standard deviation.

\section{Findings}

The respondents for the study comprised of juvenile recidivists and correctional officers sampled from Kirigiti and Wamumu rehabilitation schools in Kirinyaga and Kiambu counties of Kenya respectively. Juvenile recidivist's Socio-demographic characteristics influencing their recidivism were established. The issues analyzed were current age, highest level of education reached, parentage, school performance, occupation of caregivers, location of residence and type of house.

\section{Table 1: Current Age of Juvenile Recidivists}

\begin{tabular}{lcc}
\hline Age & $(\mathbf{F})$ & $(\mathbf{\%})$ \\
\hline 12 & 1 & 1 \\
13 & 18 & 18 \\
14 & 28 & 28 \\
15 & 47 & 47 \\
16 & 5 & 5 \\
17 & 1 & 1 \\
\hline Total & $\mathbf{1 0 0}$ & $\mathbf{1 0 0}$ \\
\hline
\end{tabular}

As shown from table 1, out of 100 respondents, majority 47 (47\%) of the juvenile recidivists indicated that they were aged 15 years old; $18(18 \%)$ of the respondents indicated that they were aged 13 years, those aged 14 comprised of $28(28 \%)$ representation, those aged 16 and 17 years old comprised of $5(5 \%)$ and $1(1 \%)$ respectively. Majority $18(90 \%)$ of correctional officers indicated that most of the recidivists were between the ages of 14-15 years. These results were interpreted to mean that majority of juvenile recidivists in the study were young children with average age of 14.5 years, standard deviation of 3.8 and modal age of 15 years. The high concentration of 
respondents in the age category of 15 years indicated that most respondents begun their delinquency life while very young children. This finding was also interpreted to mean that early onset of delinquency in children is an early indicator that child offenders will develop into habitual delinquents. The finding of this study that majority of respondents were young children was found to be similar to the finding of Mbuba (2004) that juvenile recidivists who had reoffended in the State of Louisiana in United States, 67\% of them were aged between 14-15 years.

Table 2: Highest Level of Education Reached

\begin{tabular}{lcc}
\hline Education Level & (F) & $(\mathbf{\% )}$ \\
\hline Class 5 & 19 & 19 \\
Class 6 & 45 & 45 \\
Class 7 & 27 & 27 \\
Class 8 & 4 & 4 \\
Form I & 3 & 3 \\
Form 2 & 1 & 1 \\
Form 3 & 1 & 1 \\
\hline Total & $\mathbf{1 0 0}$ & $\mathbf{1 0 0}$ \\
\hline
\end{tabular}

Out of the 100 respondents sampled for the study, majority $45(45 \%)$ of the respondents indicated that they had reached class 6, $27(27 \%)$ indicated that they reached class 7, $19(19 \%)$ of the respondents indicated they reached class 5 , while $4(4 \%)$ of the respondents indicated that they reached class 8 . Out of the 5 respondents who had reached secondary level of education, $3(3 \%)$ of the respondents had reached form one, 1(1\%) had reached form 2 and 3 respectively as shown in table 4.2. These findings were interpreted to mean that out of the 100 respondents who were sampled for the study only $5(5 \%)$ of the respondents had schooled beyond primary level of education as shown in. This was also interpreted to mean that lack of education is an indicator of offending and reoffending among children. The finding of this study that most juvenile recidivists in the study did not complete primary level of education was in line with finding of Malesi (2006) in her study on rehabilitation of juvenile adolescents in the town of Soweto in South Africa that majority of juvenile recidivists had reached grade 5 as their highest level of education.

\section{Criminality within Juvenile Recidivist's Household}

The study sought information from the respondents whether there were some members in their households who had been arrested and convicted.

Table 3: Arrests among Juvenile Recidivist's Family Members

\begin{tabular}{lllll}
\hline Family Members & \multicolumn{2}{c}{ Arrested } & \multicolumn{2}{c}{ Not Arrested } \\
\cline { 2 - 5 } & $\mathbf{( F )}$ & $\mathbf{( \% )}$ & $\mathbf{( F )}$ & $\mathbf{( \% )}$ \\
Mother & 31 & 44.93 & 38 & 55.07 \\
Father & 15 & 37.50 & 25 & 62.50 \\
Guardian & 17 & 56.67 & 13 & 43.33 \\
Brother & 23 & 25.56 & 57 & 63.33 \\
Sister & 20 & 24.39 & 62 & 75.61 \\
\hline
\end{tabular}

As shown in table 3, out of the 100 respondents in the study, 31 (44.93) indicated that their mothers had been arrested before their initial committal. $15(37.50 \%)$ of respondents who were living with their fathers indicated that their fathers had been arrested before their initial committal, while those who were living with their guardians indicated that $17(56.67 \%)$ of them had been arrested before their initial offence. $23(25.56 \%)$ out of 90 respondents who had brothers indicated that they had a brother who had been arrested for committing a criminal offence as compared to $20(24.39 \%)$ out of 82 recidivists who had their sisters arrested for criminality. This can be interpreted that majority of respondents came from household with criminality among family members which was learnt by respondents.

Table 4: Location of Juvenile Recidivist's Household

\begin{tabular}{llcccc}
\hline Social Characteristic & Operationalization & Juvenile Recidivists & \multicolumn{2}{c}{ Correctional Officers } \\
\cline { 3 - 6 } & & $\mathbf{( F )}$ & $\mathbf{( \% )}$ & $\mathbf{( F )}$ & $\mathbf{( \% )}$ \\
\hline Household setting & Rural & 40 & 40 & 9 & 45 \\
\multirow{3}{*}{ Urban Setting } & Urban & 60 & 60 & 11 & 55 \\
& Live in slum area & 48 & 80 & 18 & 90 \\
& Not in slum area & 12 & 20 & 2 & 10 \\
\hline
\end{tabular}

As shown in table 4.11, respondent who lived in urban areas were found more prone to delinquency than those who live in rural areas. Out of 100 respondents sampled for the study, $60(60 \%)$ and $11(55 \%)$ of juvenile recidivists and correctional officers indicated that majority of recidivists came from urban areas. Furthermore, the study indicated that out of 60 juvenile recidivists who lived in urban areas, $48(80 \%)$ lived in slums. The finding that majority of juvenile recidivists lived in slum areas was supported by 18 (90\%) of correctional officers. This 
finding was interpreted to mean that majority of children from slums are more prone to delinquency than those from well to areas.

Table 5: Juvenile Recidivist's with Friends before Initial Committal

\begin{tabular}{lcc}
\hline Juvenile Recidivists with Friends & $\mathbf{( F )}$ & $\mathbf{( \% )}$ \\
\hline YES & 100 & 100 \\
NO & 0 & 0 \\
\hline Total & $\mathbf{1 0 0}$ & $\mathbf{1 0 0}$ \\
\hline
\end{tabular}

As presented in table 5 all 100 (100\%) respondents sampled for the study had friends before their initial committal. This finding was interpreted to mean that respondents had social networks before initial committal from which they drew inspiration and support.

\section{Conclusions}

The objective of the study was to determine the influence of social demographic characteristics of juvenile recidivists on their reoffending. The key finding of the study was that on social characteristics of juvenile recidivists the characteristic most associated with reoffending was negative peer influence, as for demographic characteristic the characteristic most associated with recidivism was level of education reached by juveniles in Kiambu and Kirinyaga counties. It was therefore concluded that negative peer influence and level of education reached by juvenile recidivists were the socio-demographic characteristics that contributed highly to juvenile recidivism in Kiambu and Kirinyaga counties of Kenya.

\section{Recommendations}

The study sought to determine the influence of social demographic characteristics of juvenile recidivists on their reoffending. The key finding of the study was that on social characteristics of juvenile recidivists the characteristic most associated with reoffending was negative peer influence, as for demographic characteristic the Reoffending was negative peer influence, as for demographic characteristic the characteristics that was most associated with recidivism was level of education reached by juveniles in Kiambu and Kirinyaga counties It was therefore concluded that negative peer influence and level of education reached by juvenile recidivists were the sociodemographic characteristics that highly contributed to juvenile recidivism in Kiambu and Kirinyaga counties of Kenya. The study therefore recommended that programmes aiming at improving the social and economic well being of juvenile's family should be enhanced. These programmes should also encompass psychosocial support both to the juveniles and parents/guardians.

\section{REFERENCES}

Agnew, R. 1992. "Foundations of a General Strain Theory of Crime and Delinquency". Criminology, vol. 30 no. pp. 47-87

Ahuja R. (2001). Research Methods. Jaipur. Rawat Publications

Allan, G.N. (1998). Child Abuse: Different Perspectives. New York. Brick Stone and Roller publishers

Andrews, D., I. Zinger, R. H., James, B., Paul G., \& Francis T. C. (1990). "Does Correctional Treatment Work? A Clinically-relevant and Psychologically-informed Meta-analysis”. Criminology vol. 28, no. 3, pp. 369-404.

ANPPCAN (2008). Protection of Juvenile recidivist in Kenya. A paper presented at the Workshop for Key Actors in Child Protection on Juvenile recidivists at Jumuia Hotel-Kisumu. August 1-4, 2008. Unpublished

Anyangu, M. (2003). A Case Study of South Africa Rehabilitation Programs. Khulisa Management Services: Johannesburg. South Africa.

Ayaro, N. (2009). The Society Perception of the Effectiveness of Correctional Facilities and Intervention Programmes for Delinquency in Nairobi and its Environs. M. A Psychology (Counseling), University of Nairobi. Unpublished

Brezina, T. (1996). "Adapting to Strain: An Examination of Delinquent Coping Responses”. Criminology, vol. 34, no. pp. 39-60.

Bordens, K. S. (2005). Research and Design Methods). New Delhi. Tat McGraw

Borg, W.R., Gall M.D. \& Gall, J. (2010). Social Research. An Introduction. $6^{\text {th }}$ ed. New York. Longman Publishers.

Child Rights Legal Aid (2004). Street Children and Juvenile Justice in Kenya. Nairobi. Unpublished

Ching'andu, A. N. P; \& Welty, M. J. (2008), A Case Study of Hope Worldwide South Africa OVC Programme. Johannesburg. Unpublished

Clark, J. (1995). Juvenile Recidivism. Analysis of Socio-Economic Factors. Australia Journal of Social Sciences 13(1): 27-36

Cottle, C. C., Ria J. L., Kirk H. (2001). "Prediction of Criminal Recidivism in Juveniles: A Meta-Analysis". Criminal Justice and Behavior vol. 28, Issue: 3 pp.367-394

Deborah, H. (2001). Juvenile Delinquency. New York McGraw- Hill, Inc

Delamont, S. (2003). Realizing Qualitative Research. Chicago. Chicago University Press 
Dennis, E. ( 1960). The Essentials of Factor Analysis. Rinchart and Wistern

Department of Children Services (2012). Department of Children's Services Annual Report 2011-2012. Nairobi. Government Printer

Department of Children Services (2011). Guideline for Child Participation Manual. Nairobi. Government Printer

Department of Children Services (2007). Manual for Area Advisory Councils. Nairobi. Government printer

Directorate of Personnel Management (2004). Report on staffing of Department of Children Services. Nairobi. Government Printer

Eielson, S. (2007). Communication Slang among Juvenile recidivists in Kingston, Jamaica. International Journal of Criminology. Vol 14

Epstein, N. B., Lawrence M. B., and Duane S. B. (1983). “The McMaster Family Assessment Device”. Journal of Marital and Family Therapy vol. 9, no. 2, pp.171- 180.

Farrington, D. \& West, D. (1993). Cited by Everson, S. (2003). "Repeat Victimization and Prolific Offending: Chance or Choice?" International Journal of Police Science and Management vol. 5, no. 3, pp. 180-194

Gatigwa, R. (2008). Assessment of the potential of Comfrey as a source of Vitamin A for Malnourished Children. A case study of Kirigiti Approved School. M.Sc., Department of Food Technology. University of Nairobi. Nairobi. Unpublished

Gay, R. (1981). Educational Research Competencies for Analysis and Application. Upper Saddle. Prentice Hall

Glueck, S. \& Eleanor T. G. (1950). Unraveling Juvenile Delinquency, N.Y.Commonwealth Fund

Gordon, D. A., Karen G., and Jack A. (1995). "The Effect of Functional Family Therapy for Delinquents on Adult Criminal Behavior”. Journal for Criminal Justice and Behavior vol. 22, no. 1, pp. 60-73.

Gottfredson, D. M. and Michael, C. (Eds.) (1987). Prediction and Classification:Criminal Justice Decision Making. Chicago: University of Chicago Press.

Government of Kenya (2001) Children Act. Nairobi. Government Printer

Hagan, F. E. (2003). Research Methods in Criminology and Criminal Justice Allan \& Bacon, MA: Boston

Hirschi, T. (1969). Delinquency. Berkeley, CA: University of California Press

Human Rights Watch (1997). Juvenile Injustice: Police Abuse and Destruction of Street Children in Kenya. New York. Human Rights Watch.

JIKA (2009). Child Protection Manual: Minimum Standards. Nairobi. Unpublished

Kothari C.R. (2004). Research Methods Techniques. New Delhi. New Age International Publishers

Lavera L.W. (2002). Rehabilitation Process of Juvenile Delinquents in Kenyan Approved Schools. PhD Thesis. Department of Educational Psychology, Egerton University. Unpublished

Maxwell, A. (1961). Analyzing Quantitative Data. New York. John Wiley \& Sons.

Merton, R. K. (1938). "Social Structure and Anomie". American Sociological Review no. 3, pp. 672-682.

Miner, M. H. (2002). "Factors Associated With Recidivism in Juveniles: An Analysis of Serious Juvenile Sex Offenders". Journal of Research in Crime and Delinquency vol. 39, no. 4, November, pp. 421-436.

Minor, K. I., James, B. W., Irina, R.; Soderstrom, R. B., \& Deborah, W. (1999). "Sentence Completion and Recidivism Among Juveniles Referred to Teen Courts". Crime \& Delinquency vol. 45, no. 4, pp. 467-480.

Moles, G. Rowland, F. (1998). Penology. London. Oxford University Press

Morrison P. (2010). Drug and Alcohol use by Young Offenders in the State of Nevada, United States. M.A Thesis University of Colorado. Unpublished

Mpurula, W, (2006). Influence of Institutional Rehabilitation of Child Offenders in Kigali Rwanda. Kigali. United Press of Rwanda

Mugambi, A. (2005). Functions of Children's Department. In a report on Workshop on the Rights of the Kenyan Child. Nairobi. Unpublished.

Mugenda, S.O \& Mugenda, A. G. (2003). Research Methods: Quantitative and Qualitative Approaches. Nairobi: Acts Press.

Mukozi, S.W. (2010). Rehabilitation of Juvenile recidivists in Kampala City, Uganda. MA Thesis. Makerere University. Unpublished

Nachmias, C. F. \& Nachmias, D. (1996). Research Methods in the Social Sciences ( $5^{\text {th }}$ Ed). London. Arnold.

Ndirangu L.N. (2008). Rehabilitation of Disadvantaged Children in Nairobi: A comparative Study of Selected Rehabilitation Homes in Nairobi. MA Thesis, Department of Sociology, University of Nairobi.

Njuguna D.W. (2007). Rehabilitation of Juvenile Delinquents: A study of Kabete Approved School, Kenya. Diploma in Criminology. University of Nairobi. Nairobi. Unpublished

Nyamato, R.K. (2006): The Effectiveness of Boarstal Institutions in Rehabilitating Youthful Offenders: A case study of Shimo la Tewa Boarstal Institution. B.A Dissertation, Catholic University of Eastern Africa. Mombasa. Unpublished

Odegwu, O. (2008). Challenges Facing Juvenile recidivists in Juvenile Justice System in Lagos. M.A Thesis. University of Abidjan. Unpublished

Ogbonor, O. (2006). Juvenile Recidivism: Different Perspectives. Lagos. University of Lagos Press. 
Okoth, P. G. (2012). Research as a Cornerstone of Quality Assurance in University Education with Specific Reference to Uganda Martys. University Journal of Social Science and Sustainable Development. Vol.5: $37: 57$

Parker, R. N. and Kathleen A. (1998). Alcohol, Drugs, and Violence. Annual Review of Sociology, vol. 24, pp. 291-311.

Peterson S. (2009). Reforming Juvenile Justice System in Columbia. Study of Juvenile Correctional facilities in Columbia. PhD Dissertation. Unpublished.

Sebastian, B \& Byenkya, T. (2008). A Case Study of AMREF South Africa. Sekhukhune and Umkhanyakude OVC Programme. Khulisa Management Services. Johannesburg, South Africa.

Snyder, H. N. (1998). "Serious, Violent and Chronic Juvenile Offenders: An Assessment of the Extent of the Trends in Officially Recognized Serious Criminal Behavior in a Delinquent Population”. In Loeber, Rolf and D. Farrington (Eds.), Serious and Violent Juvenile Offenders: Risk Factors and Successful Interventions. Thousand Oaks, CA: Sage.

Thurman, T.R., Hoffman, A. Chatterji, M. \& Brown, L ( 2007. Causes of offending among Orphans and Vulnerable Children in Kilifi. Unpublished

Vennard, W. (1997). Adolescent Delinquency: Our Challenges. Pretoria. Educational Books Publishers

Vold, G. B., Thomas J. B., and Jeffrey B. S. (1998). Theoretical Criminology, 4th edition, Oxford University Press, Inc.

Wakanyua, S.N. (2005). Rehabilitation of Juvenile Delinquents: A survey of Approve Schools in Kenya. M.A Thesis in Sociology, University of Nairobi. Unpublished

Winter, Q. \& Ian, T. (2000). Towards a Theorized Understanding of Family Life and Social Capital. Melbourne, Australia: Australian Institute of Family Studies. 